\title{
A Paraconsistent Poem
}

\section{Jeremiah Joven Joaquin}

There once was this barber

Who shaves only those who do not shave themselves.

To this (Bertrand) Russell wondered

If that same barber could even shave himself.

There was this description,

"The smallest undefinable integer."

(G. G.) Berry's observation?

That expression defines such integer!

Epimenides once proclaimed

That all Cretans are beasts who always lie.

A weird sentence to exclaim

By a person who in Crete resides.

What, then, must we say about these notions?

All these vile contradictions of the mind?

Of course, they're inconsistent assertions,

Paradoxes that put us in a bind.

In the face of paradox, says (Kurt) Gödel,

Abandon completeness for consistency to thrive.

(Graham) Priest and (F. G.) Asenjo play a different fiddle:

Embrace contradictions and let consistency die!

The lovers of paradox may, thus, take the ultimate route:

The route of a paraconsistent logic, of the logic of paradox.

To countenance this logic implies a significant mental turnabout.

Since it denies ex falso quodlibet, it's quite unorthodox.

This paraconsistent logic may accept true contradictions

And may swallow some of them whole.

Just don't let them prove every other proposition

Lest everything explode!

\author{
Jeremiah Joven Joaquin \\ Department of Philosophy \\ De la Salle University \\ Manila \\ Philippines \\ e-mail: jeremiah.joaquin@dlsu.edu.ph
}

Publisher's Note Springer Nature remains neutral with regard to jurisdictional claims in published maps and institutional affiliations. 